\title{
The Characteristics of Climate Change in Latest 60 Years and Extreme Severe Weather in Latest 10 Years in Qinhuangdao
}

\author{
Liling $\mathrm{Ju}^{1}$, Hongming $\mathrm{Guo}^{1}$, Yun $\mathrm{Xia}^{2}$, Zhizheng $\mathrm{Mao}^{1}$ \\ ${ }^{1}$ Qinhuangdao Meteorological Bureau, Hebei province, Qinhuangdao, 066000 \\ ${ }^{2}$ Hebei Province Meteorological Bureau, Hebei province, Shijiazhuang, 050000 \\ Corresponding author:Hongming Guo,03353211613,qhdqxtghm@163.com

\section{近 60a 秦皇岛气候变化特征及近 $10 \mathrm{a}$ 灾 害天气特点}

\author{
居丽玲 ${ }^{1}$, 郭鸿鸣 ${ }^{1}$, 夏芸 ${ }^{2}$, 毛智政 ${ }^{1}$ \\ １河北省秦皇岛市气象局，河北 秦皇岛066000 \\ 2 河北省气象局，河北 石家庄 050000 \\ 通讯作者: 郭鸿鸣，0335-3211613，qhdqxtghm@163.com
}

\begin{abstract}
Based on the meteorological data in Qinhuangdao in latest 60 years and major mereorological disaster data in latest 10 years, the characteristics of climate change and occurrence of extreme severe weather in Qinhuangdao were analyzed using mathematical statistical method. To provide a climate basis for scientific planning of the development of industry, agriculture, tourism and cities, and to reduce risks and economic losses caused by meteorological disasters. The results show that the annual average temperature indicate a slow upward trend. The annual precipitation and the precipitation day show a decreasing trend, the interdecadal change of storm rainfall also shows a decreasing trend, while the change of heavy storm rainfall decreases first then increases. The annual variation of the average wind speed shows a decreasing trend, so as the annual gale day does. The studies of major meteorological disasters show that extreme weather events such as typhoon, heavy storm and extreme temperature occurred successively in Qinhuangdao in recent ten years, ranking a higher frequency than former time. As a result, the risk and impact of meteorological disasters have been aggravated. Since the extreme weather in recent ten years occurred more locally with higher intensity, the weather forecast is becoming more difficult and the meteorological risk is further enhanced.
\end{abstract}

Keyword-climate change, extreme severe weather, meteorological risk

摘要一基于近 60 年秦皇岛的气象观测资料 和近 10 年的重大气象灾情数据, 应用数学统 计方法, 分析了气候变化特征和灾害性天气的
发生特点。为科学规划工农业、旅游业和城市 的发展提供气象气候依据, 降低因气象灾害带 来的风险和经济损失。气象观测资料分析表 明: 年平均气温呈缓慢上升趋势; 年降水量和 年降水日数呈减少趋势, 暴雨年代际变化呈减 少趋势, 大暴雨年代际变化呈先减少后增加趋 势; 各气象站平均风速年际变化均呈减小趋 势, 年大风日数亦呈减少趋势。重大气象灾情 分析表明: 在近十年中, 低温、台风、特大暴 雨、高温等极端气象事件先后在秦皇岛发生, 发生的频率高于过去 50 年, 从而导致气象灾 害风险及影响程度加重。由于近十年极端性天 气多为局地性, 且强度较以往增大, 直接导致 预报难度增大, 气象风险进一步提升。

关键词一气候变化, 极端恶劣天气, 气象风 险

\section{I. 引言}

自 1980 年以来，气候变化已经成为全球 关注的热点问题, 特别是在全球气候日趋异常 的情况下, 极端天气事件导致暴雨、洪涝、干 旱、高温、低温等气象灾害频繁发生, 由于气 象灾害或其衍生灾害造成了较大的社会经济 影响, 甚至是人员伤亡。丁一汇 ${ }^{[1]}$ 等认为温度 极值的变化可能造成农作物增加，牧业受损， 
需要更多的能源制冷, 人类迁徙和由于高温天 气造成的死亡人数将增加, 同时霜日的减少将 使得与寒冷有关的人类迁徙减少, 作物的冷害 减少。秦皇岛市位于河北省东北部, 北靠燕山, 南邻渤海, 属于暖温带半干旱半湿润季节性大 陆气候, 气候变化同样对秦皇岛地区的旅游发 展、城市建设、工农业发展和人民生活产生了 一定的影响。孙丽华 ${ }^{[2]}$ 对秦皇岛市近 63 年自 然降水资源进行了分析研究, 表明秦皇岛的水 资源呈减少趋势，水资源严重圆乏。本文利用 秦皇岛 5 个国家气象站近 60 年的气温、降水、 风、相对湿度、日照等气象要素资料和部分区 域站降水数据, 以及近 10 年的重大气象灾情 数据, 应用数学统计方法, 分析了秦皇岛市近 60 年的气候变化趋势特征和近 10 年极端灾害 性天气的发生特点, 为地方政府科学规划工 业、农业、旅游、城市的发展提供气象气候依 据, 降低因气象灾害带来的风险和经济损失。
II. 秦皇岛近 $60 \mathrm{a}$ 气象要素变化分析

基于秦皇岛 5 个国家气象站 1954-2017 年, 近 60 年的气温、降水、风、相对湿度、 日照等气象要素资料, 应用数学统计方法进行 分析和研究。

\section{1 气温的变化}

对秦皇岛各县区国家站的年平均气温, 年 最高气温、年最低气温分别计算每年的五站平 均值, 并绘制成年纪变化曲线 (图 1), 可以 看出年平均气温平均值、年最高气温平均值、 年最低气温平均值均呈现出缓慢增大的趋势, 气候倾向率分别为 $0.257^{\circ} \mathrm{C} / 10 \mathrm{a} 、 0.182 / 10 \mathrm{a}$ 、 $0.456{ }^{\circ} \mathrm{C} / 10 \mathrm{a}$, 由于气温的升高, 地温、 $0^{\circ} \mathrm{C}$ 和 $10^{\circ} \mathrm{C}$ 积温逐渐增大, 初霜冻日期提前 (图 $2 \mathrm{a}$ ), 终霜冻日期延后 (图 $2 b$ ), 无霜期变短。霜冻 初、终日的稳定性对春秋季农事生产具有一定 影响, 特别是终日的不稳定性易导致春季霜冻 害及倒春寒的发生, 严重影响早春大田作物的 播种。

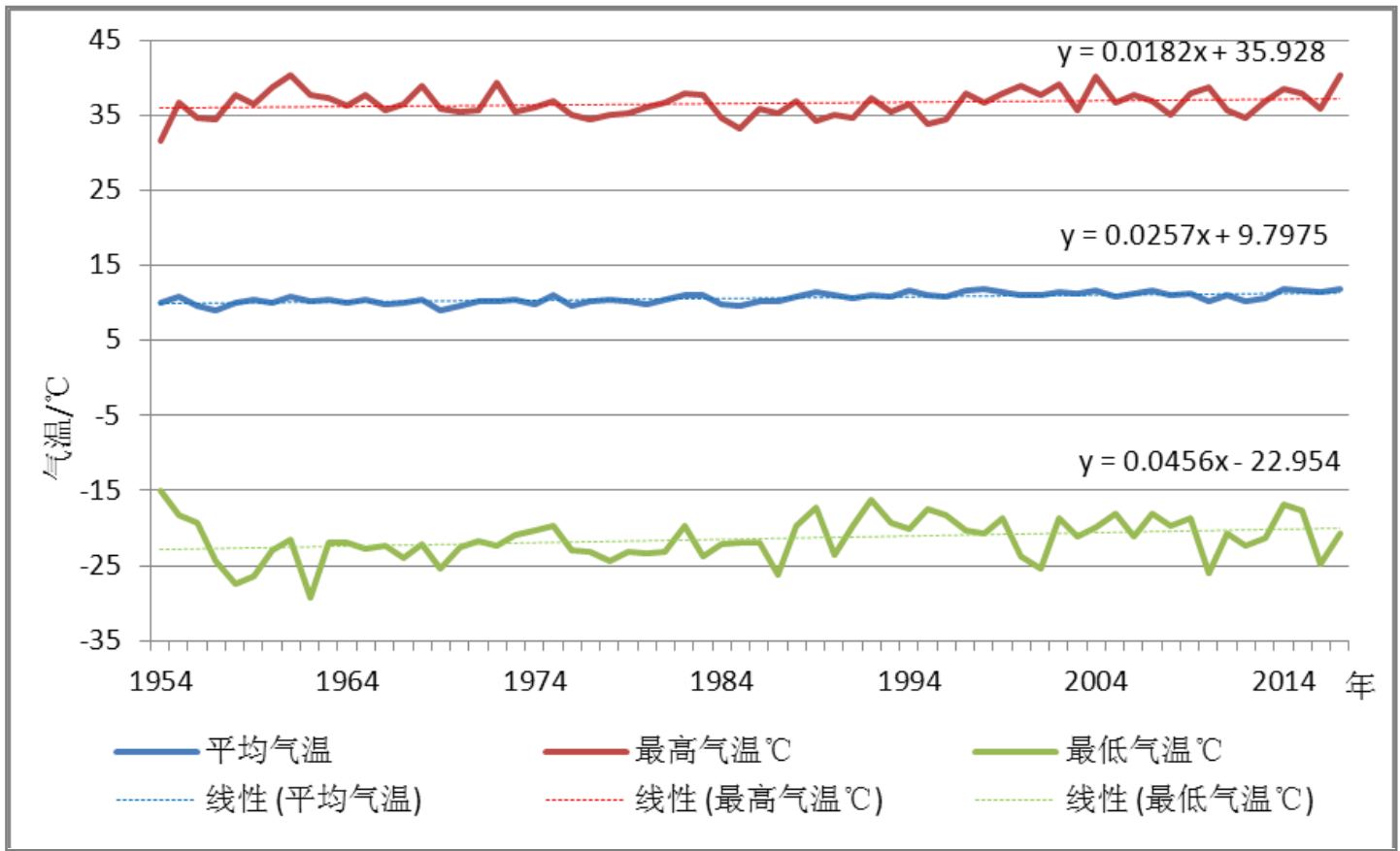

1 近 60 年气象要素变化

图 1. 秦皇岛地区年平均气温平均值、年最高气温平均值、年最低气温平均值的年纪变化 


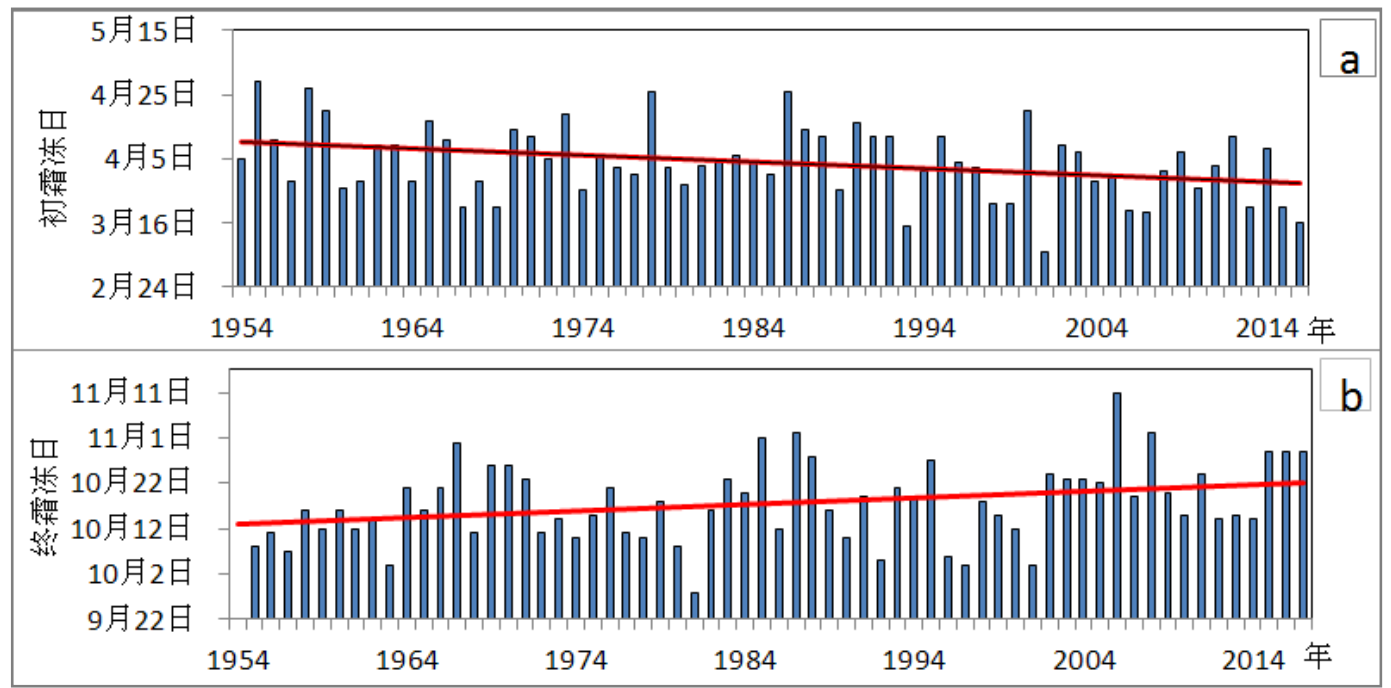

图 2 1954-2017 年秦皇岛市初霜日 (a) 、终霜日 (b) 的变化趋势

\section{2 降水的变化}

对秦皇岛全市 5 个国家气象站 1954-2017 年的降水量年平均（图 3)、降水日统计分析, 并绘制年纪变化图, 可以看出, 各县区年平均 降水量均呈减少趋势, 由于五个国家站的地理 位置相近，同年份内降水量差别不大，年平均 降水气候倾向率为 $-16 \mathrm{~mm} / 10 \mathrm{a}$, 年降水日数也
呈减少趋势, 且下降趋势较显著, 年平均降水 日气候倾向率为-4.9 天/10a。1990 年以前, 各站年降水日数在 80-120 日之间波动，没有 明显的趋势变化, 自 1990 年以后, 年降水日 数呈现明显的波动下降的趋势。暴雨年代际 （10 年）变化呈减少趋势, 大暴雨呈现先减 少后增减的变化趋势（表 1 ）。

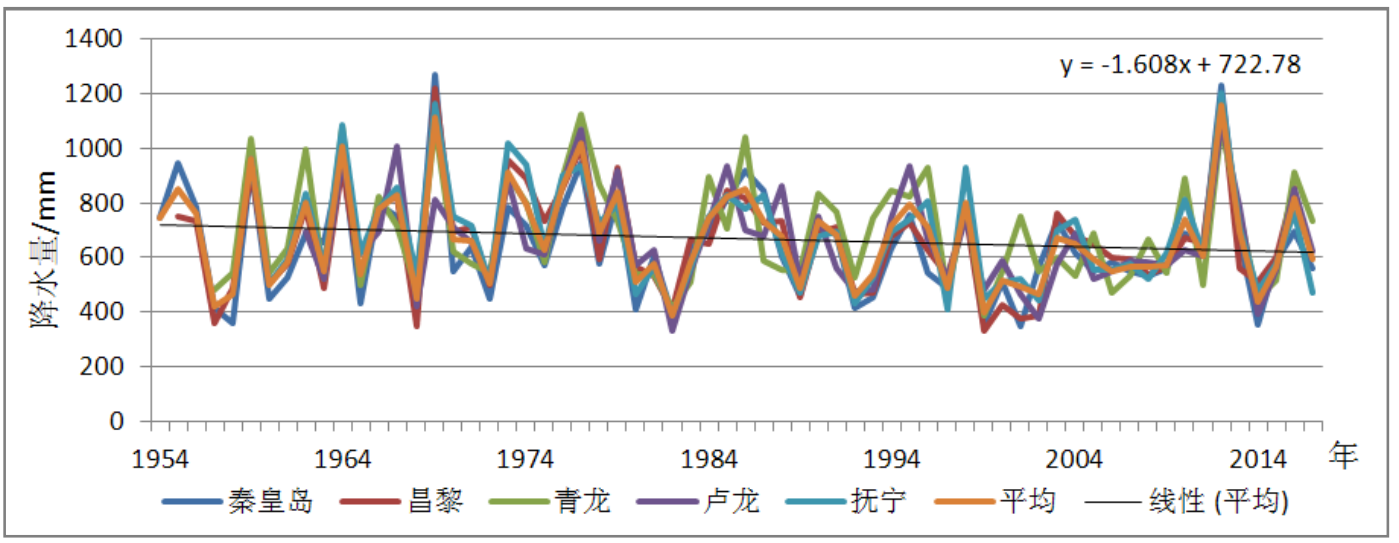

图 3 1954-2017 年秦皇岛各县区年降雨量变化趋势

表 1 秦皇岛全市暴雨、大暴雨的年代际统计

\begin{tabular}{ccccccc}
\hline 年代 & $1960-1969$ & $1970-1979$ & $1980-1989$ & $1990-1999$ & $2000-2009$ & $2010-2017$ \\
\hline 暴雨 & 125 & 153 & 98 & 113 & 104 & 110 \\
大暴雨 & 27 & 32 & 19 & 24 & 12 & 32 \\
\hline
\end{tabular}




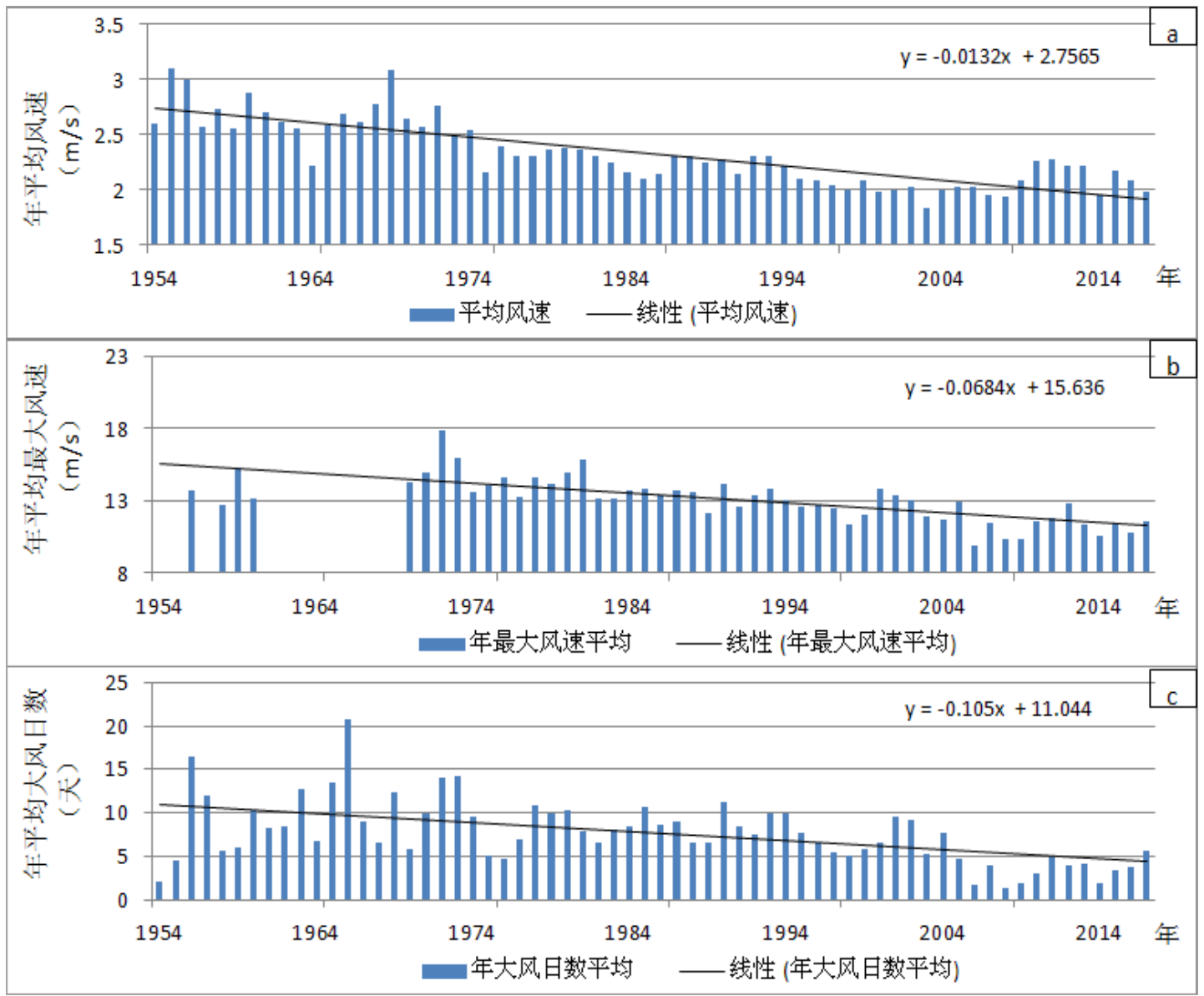

图 4 1954-2017 年秦皇岛平均风速 (a)、年最大风速平均 (b)、年大风日数 (c) 平均变化趋势

2.3 风的变化

对 1954-2017 近 64a 的秦皇岛 5 个国家 站年平均风速、年最大风速、年大风日数做算 术平均（图 4)，可以看出，平均风速、年最 2.4 相对湿度的变化

全市年平均相对湿度在 55\%-72\%之间（图
大风速、年大风日数均呈现下降趋势，气候倾 向率分别为 $-0.132(\mathrm{~m} / \mathrm{s}) / 10 \mathrm{a} 、-0.684(\mathrm{~m} / \mathrm{s})$ /10a、 -1.05 天 $/ 10 \mathrm{a}$ 。

5 )，平均值为 $60.91 \%$ 。相对湿度年际变化表 现为市区呈增大趋势, 其他县区为减小趋势。

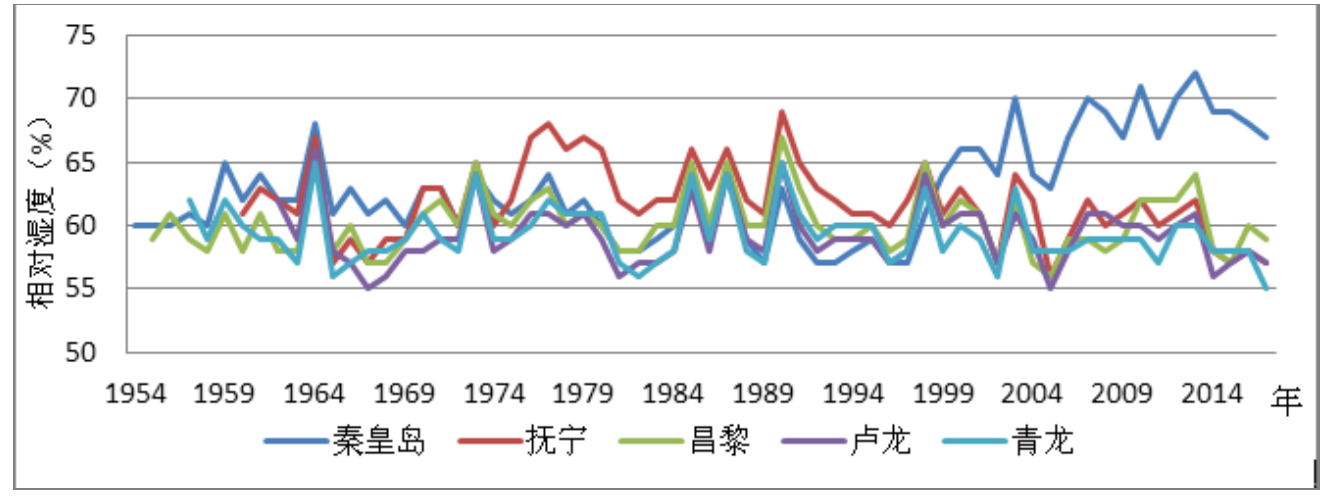

图 5 1954-2017 年秦皇岛各县区年平均相对湿度年际变化 


\section{5 日照的变化}

对秦皇岛各县区日照时数月变化趋势分 析表明, 一年中 3-5 月、9 月日照时数相对较 高, 7 月、11-1 月份日照时数相对较低, 由此 说明夏季多降水、冬季多雾霧等因素是日照时 数偏少的主要影响因子。通过对 1954-2017 年 秦皇岛地区日照时数年变化特征分析可以看 出（图 6), 东北部（青龙、抚宁、秦皇岛的 平均值）和西南部（卢龙、昌黎的平均值）在 1990 年以前变化趋势基本相同, 均呈现减少 趋势, 但此后, 西南部逐渐增加再减少, 东北 部继续较少后增加。日照平均呈现较少趋势,
气候倾向率为 -25 小时 $/ 10 a$, 日照时数的较少 对于农作物的生长略有不利影响。但春季 3-5 月的秦皇岛平均日照时数年变化趋势略有增 加, 气候倾向率为 2.8 小时 $/ 10 \mathrm{a}$, 其他季节均 有不同程度的减少。

\section{III. 近 10 年重大气象灾情数据分析}

对 2006-2017 年气象灾情数据（暴雨、大 风、强对流）进行分县统计统计（图 7)，暴 雨导致的灾情多发生在西部和北部, 大风导致 的灾情多发生西部和南部，对流（雷电、冰雱） 导致的灾情多发生在西部和南部。

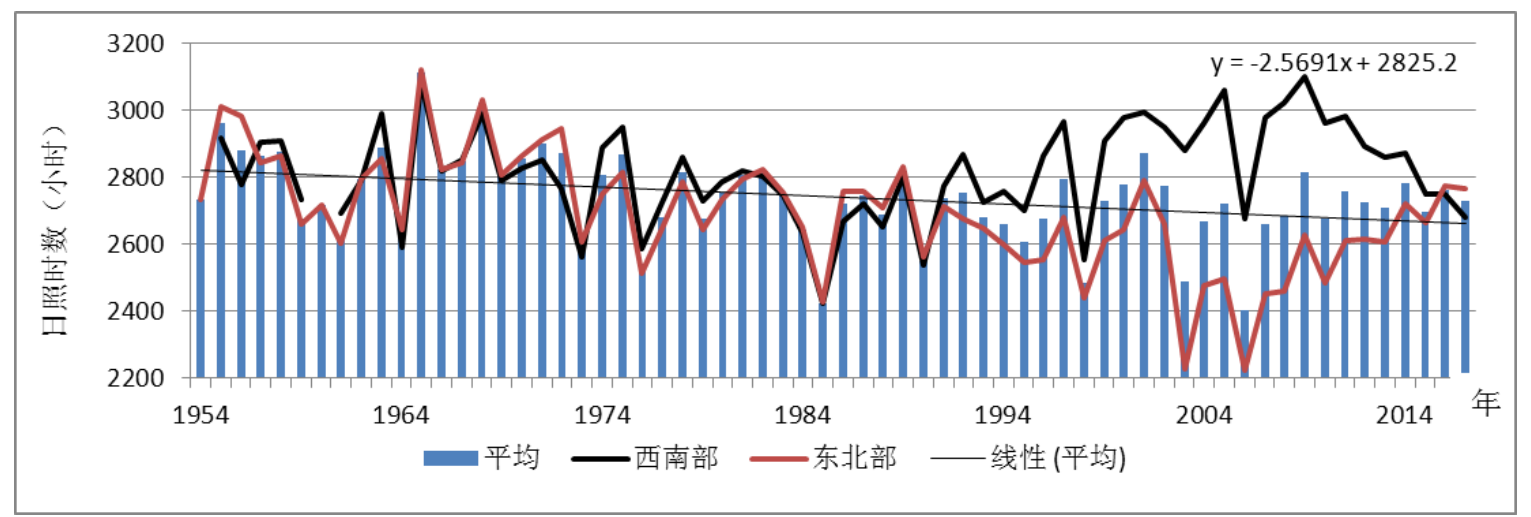

图 6 1954-2017 年秦皇岛全市年平均日照时数年际变化
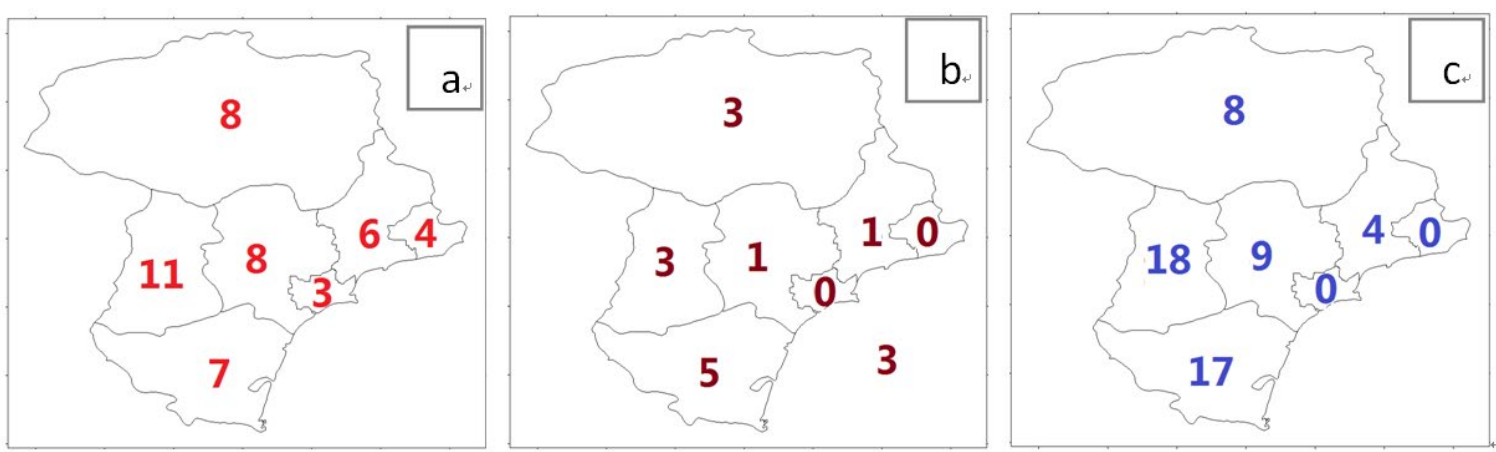

图 7 2006-2017 年秦皇岛各县区暴雨（a)、大风（b)、强对流（c）气象灾害发生次数统计

2010-2018 年秦皇岛发生的历史极端灾害 性天气主要如下:

（1） 2010 年 1 月 6 日早晨秦皇岛、卢龙 最低气温突破了历史极值, 秦皇岛达到了 $-26.0^{\circ} \mathrm{C}$, 受极端低温影响, 秦皇岛海区出现多 年少有的严重海冰现象, 导致海上航线, 港口 作业严重受阻。

（2）2012 年 8 月第 10 号台风 “达维” 影响秦皇岛, 此次台风是建国以来, 登录长江 以北最强的台风, 叠加天文大潮, 降水无法及
时排入大海, 造成秦皇岛市海港区、山海关区 和北戴河区出现严重内涝, 交通㿈疾, 由东北 经过山海关的铁路全部停运。

(3)2016 年 7 月祖山出现历史特大暴雨, 24 小时降雨量达到 614 毫米 (区域自动站数 据), 该记录成为秦皇岛地区有气象记录以来, 日降雨量的最大值。

（4） 2017 年 6 月 15 日秦皇岛地区出现 极端高温天气, 除昌黎外, 其他四个国家气象 站均突破历史极值, 为有气象记录以来的历史 
最高气温, 北戴河避暑圣地也出现了 $40^{\circ} \mathrm{C}$ 的 高温数值。

（5） 2018 年夏季副高异常偏北， 7 月第 10 号台风 “安比” 过境秦皇岛青龙县, 成为 了秦皇岛地区首个过境台风的记录。

（6）2016年 6 月 8 日, 秦皇岛遭遇近十 年最强冰霄天气影响, 影响范围包含所有县 区, 抚宁出现近乎鸡蛋大小的冰雱, 造成严重 经济损失。

（7）2012 年 11 月 3 日, 秦皇岛出现了 有气象记录以来最晚的暴雨天气, 局地出现大 暴雨, 同样造成较大的经济损失。

短短十年左右时间, 秦皇岛地区的极端天 气发生的频率高于以往过去, 从而导致气象灾 害风险及影响程度加重。虽然国家气象站统计 降水、风速、暴雨日数、大风日数的年际变化 均为降低或减少的趋势, 造成的灾害性天气理 应减少, 但是极端灾害性天气的发生反而是增 加的现象, 说明近十年极端性天气多为局地 性, 且强度较以往增大, 直接导致预报难度增 大, 气象风险进一步提升。

\section{IV. 结论}

通过对秦皇岛近 60 年气温、降水等气象 要素资料数据, 以及近 10 年的重大气象灾情 数据, 分析了秦皇岛市气候变化特征和近 10 年极端灾害性天气的发生特点, 结论如下:

（1）5 个国家气象站分析结果表明年平均气 温、年最高气温、年最低气温均呈缓慢上升趋 势, 平均气温气候倾向率为 $+0.25^{\circ} \mathrm{C} / 10 \mathrm{a}$, 由 于气温的升高, 地温、 $0^{\circ} \mathrm{C}$ 和 $10^{\circ} \mathrm{C}$ 积温逐渐增 大, 初霜冻日期提前, 终霜冻日期延后, 无霜 期变短;

（2）年降水量和年降水日数呈减少趋势, 平 均降水气候倾向率为 $-16 \mathrm{~mm} / 10 \mathrm{a}$, 暴雨年代际

(10 年) 变化呈减少趋势, 大暴雨年代际 (10 年）变化呈先减少后增加趋势;

（3）相对湿度年际变化表现为市区呈增大趋 势, 其他县区为减小趋势;

（4）各气象站平均风速年际变化均呈减小趋 势, 年大风日数亦呈减少趋势;

（5）年日照时数呈减少趋势, 但春季 3-5 月 日照日数呈增加趋势;

（6）近十年中，极端低温、台风、特大暴雨、
极端高温等极端气象事件先后在秦皇岛发生, 充分说明极端天气发生的频率高于过去 50 年，导致气象灾害风险及影响程度加重;

(7) 国家气象站统计的降水、风速、暴雨日 数、大风日数的年际变化均为降低或减少的趋 势, 造成的灾害性天气理应减少，但是极端灾 害性天气的发生反而是增加的现象, 说明近十 年极端性天气多为局地性, 且强度较以往增 大, 直接导致预报难度增大, 气象风险进一步 提升。

\section{致谢}

本项目受秦皇岛市气象局重点工作技术 支撑团队（编号：ZD201702）资助。

参考文献

[1] 丁一汇, 张锦, 宋亚芳. 天气和气候极端事件的变化 及其与全球变暖的联系. 气象, 28(3) : 3-7, 2002.

[2] 孙丽华, 齐义君, 张宝贵, 等. 秦皇岛市近 63 年自然降 水资源变化特征。中国环境管理干部学院学 报, 27 (6) : 35-38, 2017.

[3] 王晓荣, 杨丹, 邵银龙. 南京市近 60 年气候变化特征 分析. 水资源与水工程学报, 27 (4) : 119-124, 2016 .

[4] 任小玢, 董治宝, 周正朝. 近 50 年来四川盆地降水日 数的时空变化特征. 水土保持通 报, 32(4):65-70, 2012.

[5] 刘莉红, 翟盘茂, 郑祖光. 中国北方夏半年最长连续 无降水日数的变化特征.气象学 报, 66 (3) : 474-477, 2008.

[6] 梅伟, 杨修群. 我国长江中下游地区降水变化趋势分 析. 南京大学学报 (自然科学) , 41 (6) :577-589, 2005.

[7] 张海娜, 高杰. 辽宁省近 48 年降水变化特征研究. 安 徽农业科学, 39 (15): 9102-9103, 2011.

[8] 孙丽华, 张宝贵. 秦皇岛区域几类极端天气气候灾害 的特征分析及防灾减灾探讨. 中国环境管理干部学院 学报, 17 (2): 57-60, 2007.

[9] 许世远, 王军, 石纯, 等. 沿海城市自然灾害风险研究. 地理学报, 61 (2): 127-138, 2006.

[10] 章国材. 气象灾害风险评估与区划方法. 北京: 气象 出版社, 2010 . 